\title{
PERBANDINGAN ESTIMASI ANGGARAN BIAYA ANTARA METODE BOW, SNI DAN PERHITUNGAN KONTRAKTOR
}

\author{
Bambang Pilutomo ${ }^{1 *}$, dan Hammam Rofiqi Agustapraja ${ }^{2}$ \\ 1,2 Universitas Islam Lamongan \\ Jl. Veteran No. 53 A Lamongan Jawa Timur 62211 \\ 11E-mail: bambang.asuka@gmail.com² E-mail: hammamrofiqi@unisla.ac.id
}

\begin{abstract}
Abstrak
Dalam menentukan harga suatu pekerjaan, diperlukan sarana dasar perhitungan harga satuan yaitu analisa biaya konstruksi. Dalam menghitung analisa biaya konstruksi selama ini memakai analisa BOW, SNI dan perhitungan kontraktor. Diperlukan studi komparasi dari ketiga metode tersebut sehingga diketahui mana yang lebih efektif dan efisien sebagai dasar bagi semua pihak dalam menentukan strategi dalam hal estimasi anggaran biaya. Penelitian dilakukan dengan menyusun Rencana Anggaran Biaya proyek berdasarkan volume pekerjaan pada bill of quantity (BoQ) tender. Analisa harga satuan pekerjaan dihitung berdasarkan analisa BOW, analisa SNI dan analisa versi Kontraktor. Dari hasil estimasi tersebut diperoleh harga berdasarkan analisa BOW sebesar Rp. 2.682.315.013,-, berdasarkan SNI sebesar Rp. 1.958.002.381,- dan berdasarkan perhitungan kontraktor sebesar Rp. 1.781.956.483,-. Selisih harga BOW dengan SNI Rp. 724.312.632,-. Selisih harga BOW dengan perhitungan kontraktor sebesar Rp. 900.358.529,-. Selisih harga SNI dengan harga perhitungan kontraktor Rp. 176.045.897,--.
\end{abstract}

Kata kunci: Estimasi, RAB, SNI, BOW, Perhitungan Kontraktor

\begin{abstract}
In determining the price of a job, it need the basic tool of unit price analysis, namely the analysis of construction costs. In calculating the analysis of construction costs there are several method have been generally used such as analysis of BOW, SNI and also companies their own calculation analysis. Comparative studies are needed from the three methods so that it can be seen which is more effective and efficient as a basis for all parties in determining the strategy of cost budget estimates. The study was conducted by preparing a project cost budget plan based on the volume of works on the bill of quantity (BoQ). The unit price analysis is calculated based on BOW analysis, SNI analysis and Contractor version analysis. From the estimation results, a price based on BOW analysis is IDR 2,682,315,013,-, based on SNI analysis is IDR 1,958,002,381, - and based on analysis of contractor calculations is IDR 1,781,956,483. Difference in price between BOW and SNI is IDR 724,312,632. Difference in price between BOW and contractors calculation is IDR 900,358,529. Difference price between SNI and contractors calculation is IDR 176,045,897.
\end{abstract}

Keywords: Estimation, RAB, SNI, BOW, Contractor Calculation

\section{PENDAHULUAN}

\section{Latar Belakang}

Secara umum, metode manajemen proyek yang seringkali juga disebut dengan istilah tahapan manajemen proyek terdiri dari 5 tahapan yaitu inisiasi proyek, perencanaan proyek, pelaksanaan proyek, pengontrolan proyek dan penutupan proyek (Imam Heryanto \& Totok Triwibowo, 2009). Pada tahap perencanaan ada satu kegiatan yang sangat penting dan krusial yaitu memperkirakan biaya yang akan dibutuhkan untuk menyelesaikan proyek tersebut. Jika perkiraan terlalu tinggi kemungkinan besar akan kalah dalam tender. Perkiraan yang terlalu rendah pun sangat riskan, walaupun bisa menang dalam tender (Budi Santoso, 2009). Oleh karena itu, diperlukan pemilihan metode estimasi 
anggaran biaya konstruksi yang akurat, mudah dan tidak mahal dalam penggunaanya. Secara umum ada beberapa metode yang dipakai untuk menentukan biaya konstruksi yaitu Analisa BOW (Burgeslijke Openbare Werken, ditetapkan 28 Februari 1921), Analisa SNI (Standar Nasional Indonesia) maupun Perhitungan Kontraktor sendiri.

Ketiga analisa tersebut saling terkait dalam arti memiliki kesamaan dalam sistem penyusunan koefisien, namun berbeda nilai koefisienya tergantung dari berbagai hal misalnya penentuan tingkat efisiensi penggunaan material, efektifitas dan produktifitas tenaga kerja dan penggunaan peralatan kerja sesuai metode kerja yang dipakai.

\section{Rumusan Masalah}

Berdasarkan pada uraian latar belakang di atas, perumusan masalah dalam penelitian ini adalah berapakah selisih hasil perhitungan anggaran biaya yang dibuat berdasarkan analisa BOW, analisa SNI dan perhitungan Kontraktor?

\section{Batasan Masalah}

Untuk mempertajam ruang lingkup penelitian, maka penulis menetapkan batasan masalah sebagai berikut :

1. Menghitung analisa biaya konstruksi pekerjaan stuktur beton pada Tender Shipout Cement Debottlenecking Project. Sebagai Owner proyek adalah PT. Solusi Bangun Indonesia (Semen Indonesia Group)

2. Analisa yang dipakai adalah analisa BOW, analisa SNI dan perhitungan Kontraktor. Kontraktor dalam hal ini adalah PT. Asuka Engineering Indonesia.

3. Harga satuan material dan upah yang dipakai adalah harga satuan untuk wilayah Kabupaten Tuban, Jawa Timur tahun 2020.

\section{Tujuan Penelitian}

Tujuan dari penelitian ini adalah untuk mengetahui selisih harga hasil perhitungan anggaran biaya yang dibuat berdasarkan analisa BOW, analisa SNI dan perhitungan Kontraktor.

\section{Manfaat Penelitian}

Bagi perusahaan jasa konstruksi, khususnya Kontraktor, diharapkan bisa memberikan tambahan wawasan dalam menentukan metode dan strategi yang tepat dalam hal penghitungan anggaran biaya proyek.

\section{Tinjauan Pustaka}

Di dalam pelaksanaan proyek, selalu dibatasi oleh tiga hal yang sifatnya saling mempengaruhi dan biasa disebut segitiga project constraint yaitu lingkup pekerjaan (scope), waktu dan biaya. Keseimbangan ketiga konstrain tersebut akan menentukan kualitas suatu proyek. Perubahan salah satu atau lebih faktor tersebut akan mempengaruhi setidaknya satu faktor lainnya. Melihat segitiga project constraint, manajemen biaya mempunyai peranan yang penting dalam menentukan keberhasilan sebuah proyek.

Tahap perencanaan proyek merupakan tahap yang sangat krusial dimana manajemen biaya berperan dalam membuat estimasi biaya proyek. Penentuan metode analisa yang digunakan menjadi sangat penting sebagai dasar pembuatan estimasi biaya proyek. Metode yang dipakai sebagai dasar penentuan harga dalam estimasi biaya proyek diantaranya Analisa BOW dan Analisa SNI. Dalam perkembanganya, Kontraktor melakukan penyesuaian-penyesuaian dari kedua analisa tersebut dengan tujuan untuk mendapatkan estimasi biaya proyek yang mendekati realita, kondisi aktual dan kebutuhan di lapangan.

\section{Estimasi Anggaran Biaya}

Estimasi anggaran biaya bisa diartikan sebagai proses perhitungan volume pekerjaan, harga dari berbagai macam bahan dan pekerjaan yang akan terjadi pada suatu konstruksi (soedradjat, 1984). Estimasi anggaran biaya dihitung berdasarkan gambargambar, spesifikasi-spesifikasi terkait dan juga data-data tambahan semisal data tambahan saat survey lokasi.

1. Jenis-jenis estimasi (M. Afif Salim, 2017)

a. Estimasi kasar

Estimasi ini merupakan estimasi harga awal dan belum terlalu detail. Estimasi ini dibutuhkan oleh pemilik proyek yang selanjutnya akan dijadikan dasar untuk memutuskan apakah ide proyek akan dilanjutkan atau tidak.

b. Estimasi pendahuluan

Estimasi ini lebih detail dari estimasi sebelumnya. Estimasi ini dibuat berdasarkan gambar, rencana kerja dan syarat-syarat (RKS).

c. Estimasi detail

Estimasi detail dilakukan oleh kontraktor setelah menerima dan mempelajari dokumen tender saat aanwijzing (rapat penjelasan pekerjaan). Dokumen tender tersebut dibuat oleh konsultan perencana, biasanya terdiri dari gambar bestek, RKS dan metode pelaksanaan. Estimasi ini juga sudah 
mempertimbangkan

berbagai

kemungkinan yang akan menimbulkan

biaya, termasuk kondisi area, tingkat kesulitan pekerjaan, ketersediaan material dan sebagainya.

d. Biaya sesungguhnya

Harga yang tercantum di dalam kontrak merupakan fixed cost bagi pemilik proyek dan merupakan biaya terakhir yang nantinya dikeluarkan untuk proyek tersebut. Kecuali jika di tengah-tengah pelaksanaan proyek ada perubahan dan modifikasi desain, maka dilakukan addendum atau penyesuaian harga. Bagi kontraktor, harga dalam kontrak merupakan penerimaan fixed yang diterima dari pemilik proyek. Namun yang tahu real cost dari proyek tersebut adalah kontraktor. Kontraktor menentukan real cost dengan teliti di awal sebelum pengajuan penawaran harga ke pemilik proyek.

2. Unsur utama estimasi (M. Afif Salim, 2017)

Unsur utama estimasi bisa diartikan sebagai komponen pokok yang mempengaruhi hasil akhir nilai di dalam menentukan harga dari suatu pekerjaan. Unsur-unsur utama di dalam estimasi biaya proyek meliputi ;

a. Harga material

Analisis dilakukan meliputi perhitungan kuantiti dan harga material yang digunakan pada proses konstruksi. Material yang di analisis termasuk di dalamnya adalah material utama dan material penunjang (consumeable).

b. Upah Tenaga Kerja

Estimasi biaya upah tenaga kerja membutuhkan kemampuan, keterampilan, pengalaman dan wawasan yang baik dari seorang Estimator. Hal tersebut karena di dalam estimasi upah tenaga kerja banyak faktor yang harus dipertimbangkan seperti tingkat kesulitan pekerjaan, produktivitas pekerja, kondisi cuaca saat proses konstruksi, kenaikan UMK.

c. Biaya Peralatan

Estimasi biaya peralatan meliputi biaya pembelian dan sewa semua peralatan yang dipakai dalam proyek, termasuk biaya mobilisasi, demobilisasi, biaya pemasangan, biaya pembongkaran dan biaya operasional alat selama proyek berlangsung. Agar biaya peralatan yang timbul tidak menyerap biaya yang terlalu tinggi, peralatan yang dipakai harus sesuai dengan kapasitas yang dibutuhkan, metode yang dipakai dan spesifikasi lainya.

d. Biaya tidak langsung

Biaya tidak langsung (indirect cost) bisa berupa biaya umum (overhead cost) maupun biaya proyek. Termasuk biaya umum umum diantaranya gaji staff, sewa kantor, biaya telepon, internet dan lain-lain. Biaya proyek diantaranya premi asuransi proyek, biaya jaminan pelaksanaan, dan lainlain.

e. Keuntungan Perusahaan

Keuntungan perusahaan tergantung dari kebijakan dan strategi yang diterapkan oleh perusahaan. Beberapa faktor yang menjadi pertimbangan dalam menentukan keuntungan diantaranya kondisi persaingan, tingkat minat perusahaan, tingkat kesulitan pelaksanaan dan lain-lain.

3. Metode Analisa Biaya

a. Analisa BOW

Menurut Hammam Rofiqi Agustapraja (2017:2) analisa berdasarkan BOW (Burgerlijke Openbare Werken) ialah suatu ketentuan yang ditetapkan dir. BOW pada zaman pemerintahan Belanda. Namun bila di tinjau dari perkembangan industri konstruksi saat ini, analisa biaya BOW belum memuat pekerjaan beberapa jenis bahan bangunan yang di temukan di pasaran material bangunan dan konstruksi dewasa ini. Disamping itu analisa tersebut hanya dapat digunakan untuk pekerjaan padat karya yang peralatan konvensional. Sedangkan bagi pekerjaan yang menggunakan peralatan modern atau alat berat, analisa biaya BOW yang tidak relevan lagi dengan kebutuhan pembangunan, baik bahan maupun upah tenaga kerja. Namun demikian analisa biaya BOW masih dapat digunakan sebagai pedoman dalam penyusunan anggaran biaya.

Sistem koefisian harga satuan pekerjaan tersebut ditetapkan pada zaman pemerintahan Hindia Belanda, tepatnya tanggal 28 Februari 1921. Angka koefisien sebagai pengali meliputi 3 hal yaitu koefisien untuk harga material, upah tenaga kerja dan biaya peralatan kerja. Analisa ini menjadi dasar penentuan Rencana Anggaran Biaya pada masa itu. Analisa BOW lebih bersifat padat karya jika dibandingkan dengan analisa SNI. Saat 
ini, analisa BOW sudah jarang dipakai di dalam penyusunan rencana anggaran biaya.

b. Analisa SNI

Menurut Mohammad Riski Setio Budi (2017), analisa SNI adalah sistem koefisian harga satuan pekerjaan yang merupakan pengembangan dan pembaruan dari analisa BOW. Analisa SNI dikeluarkan oleh Pusat Penelitian dan Pengembangan Permukiman. Sistem penyusunan biaya dengan menggunakan analisa SNI ini hampir sama dengan sistem perhitungan dengan menggunakan analisa BOW. Prinsip yang mendasar pada metode SNI adalah, daftar koefisien bahan, upah dan alat sudah ditetapkan untuk menganalisa harga atau biaya yang diperlukan dalam membuat harga satu satuan pekerjaan bangunan.

Analisa SNI banyak dipakai untuk menyusun rencana anggaran biaya pada proyek-proyek pemerintah, BUMN dan swasta.

c. Perhitungan Kontraktor

Perhitungan kontraktor bisa diartikan sebagai sistem perhitungan rencana anggaran biaya yang dilakukan oleh kontraktor dengan mengacu pada sistem koefisien yang mereka tetapkan sendiri. Penetapan angka koefisien berdasarkan pada pengalaman kontraktor, metode kerja yang dipakai, lokasi pekerjaan, adat istiadat masyarakat setempat, dan lain sebagainya. Di sini, masing-masing kontraktor akan memiliki sistem perhitungan rencana anggara biaya yang berbeda-beda. Hal tersebut menjadi daya jual dan daya saing sebuah perusahaan kontraktor terutama di dalam proyek-proyek swasta. Efektifitas dan efisiensi dalam rencana anggaran biaya menjadi sangat penting dalam memenangkan kontestasi tender.

\section{METODE PENELITIAN}

1. Obyek Penelitian

Obyek dalam penelitian ini adalah tender Shipout Cement Debottlenecking Project. Proyek ini meliputi pekerjaan Sipil, Arsitektur, Mekanikal dan Elektrikal. PT. Solusi Bangun Indonesia, Tbk. , bermaksud untuk memasang fasilitas jalur pengeluaran baru untuk semen, khusus dari semen silo 4 dan 5 ke mesin pengepakan yang baru (Ex-Batam Plant) dengan kapasitas 2400 bph. Kemudian memasang transport equipment untuk semen bag dari mesin pengepakan baru tersebut ke alat palet baru dengan kapasitas 2400 bph. Fasilitas yang dibangun termasuk bangunan untuk packer, gallery conveyor dan bangunan untuk gudang semen bag dan pallet.

Fokus dalam penelitian ini adalah pekerjaan struktur beton pada tender Shipout Cement Debottlenecking Project. Tujuan pengambilan sampel hanya pada pekerjaan struktur beton saja karena agar dalam penelitian ini lebih fokus dan bisa dibandingkan secara berimbang antar metode analisa yang diteliti.

2. Jenis \& sumber Data

a. Data Primer

Data primer adalah data penelitian yang diperoleh secara langsung dari sumbernya. Data primer diperoleh melalui wawancara langsung, diskusi maupun pengumpulan data-data tender. Data primer yang diperoleh untuk penelitian ini diantaranya :

1. Gambar rencana

2. Dokumen Aanwijzing yang berisi :

- Deskripsi Proyek

- Informasi Lokasi Proyek

- Ruang Lingkup Pekerjaan

- Jadwal Pelaksanaan Pekerjaan

- Flow Proses Diagram

- Bill of Quantity

- Safety Requirement

3. Foto-foto survey lapangan

4. Daftar harga satuan material, upah tenaga kerja dan peralatan.

5. Rincian Anggaran Biaya (RAB) Kontraktor

b. Data Sekunder

Data sekunder adalah data penelitian yang diperoleh secara tidak langsung, misalnya buku, skripsi yang sejenis, journal-journal dan hasil penelitian-penelitian sebelumnya. Cara memperoleh data tesebut diantaranya dengan membaca buku-buku terkait, membaca skripsi yang sejenis, 
Bambang Pilutomo $^{1 \star}$, dan Hammam Rofiqi Agustapraja ${ }^{2}$

membaca journal-journal terkait, membaca penelitian-penelitian terkait. Selain itu, penulis juga mencari informasi tambahan di internet (googling).

\section{Waktu \& Lokasi Penelitian} 2020.

Waktu penelitian dilakukan pada tahun

Lokasi penelitian :

1. Di Tuban, terkait dengan lokasi proyek yang berada di PT. Solusi Bangun Indonesia yang beralamat di Kecamatan Tambakboyo Kabupaten Tuban, Jawa Timur.

2. Di Gresik, terkait alamat Kontraktor yaitu PT. Asuka Engineering Indonesia yang beralamat di Manyar Raya Resort blok A2 no. 8 Kecamatan Manyar Kabupaten Gresik, Jawa Timur.

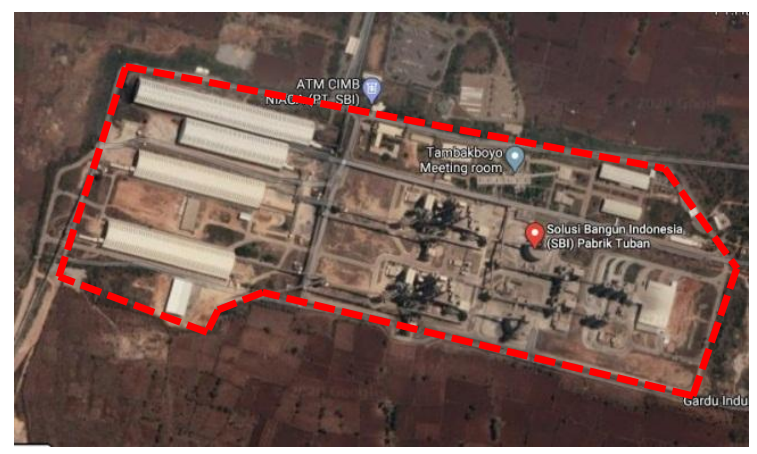

Gambar 1. Lokasi Proyek

(Sumber : Google Maps, diakses tanggal 3 Mei 2020 jam 22.46 WIB)

TQ Ship out Cement Debottlenecking Detail Lokasi Proyek

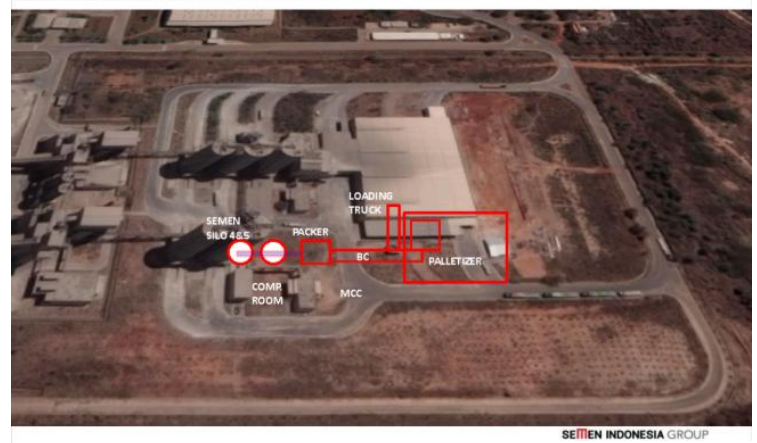

Gambar 2. Detail Lokasi Proyek

(Sumber : Dokumen Tender TQ Shipout Cement Debottlenecking, 2019)

\section{Teknik Pengumpulan Data}

Teknik pengumpulan data yang dilakukan dalam penelitian ini adalah sebagai berikut :
1. Mengumpulkan data-data tender yang diterima oleh Kontraktor diantaranya gambar rencana, dokumen aanwijzing dan foto-foto survey lokasi.

2. Melakukan survey harga satuan material, upah tenaga kerja dan peralatan di daerah Tuban, Jawa Timur.

3. Meminta data perhitungan Rencana Anggaran Biaya yang dihitung oleh Kontraktor.

4. Wawancara dan diskusi dengan pihak terkait.

\section{Teknik Analisa Data}

Analisa data di dalam penelitian ini dilakukan dengan menggunakan bantuan komputer, terutama program Microsoft Excell. Sebelum melakukan analisa dengan menggunakan komputer, penulis melakukan tahapantahapan sebagai berikut :

1. Mengumpulkan, mempelajari dan membuat rangkuman literatur terkait dengan manajemen proyek dan estimasi anggaran biaya.

2. Mengumpulkan dan mempelajari data tender pekerjaan Shipout Cement Debottlenecking Project, baik data dari Owner maupun dari Kontraktor.

3. Mengumpulkan data analisa BOW dan analisa SNI.

Selanjutnya, analisa data yang dilakukan dengan Microsoft excel sebagai berikut :

1. Menganalisa harga satuan material, upah tenaga kerja dan biaya peralatan.

2. Menganalisa harga satuan pekerjaan yang diteliti. Fokus penelitian adalah harga satuan untuk pekerjaan struktur beton.

3. Membandingkan hasil analisa harga antara harga pekerjaan yang dihitung berdasarkan analisa BOW, analisa SNI dan perhitungan Kontraktor.

\section{Diagram Alur Penelitian}

Gambar 3 berikut ini adalah diagram alir yang digunakan di dalam penelitian ini. 


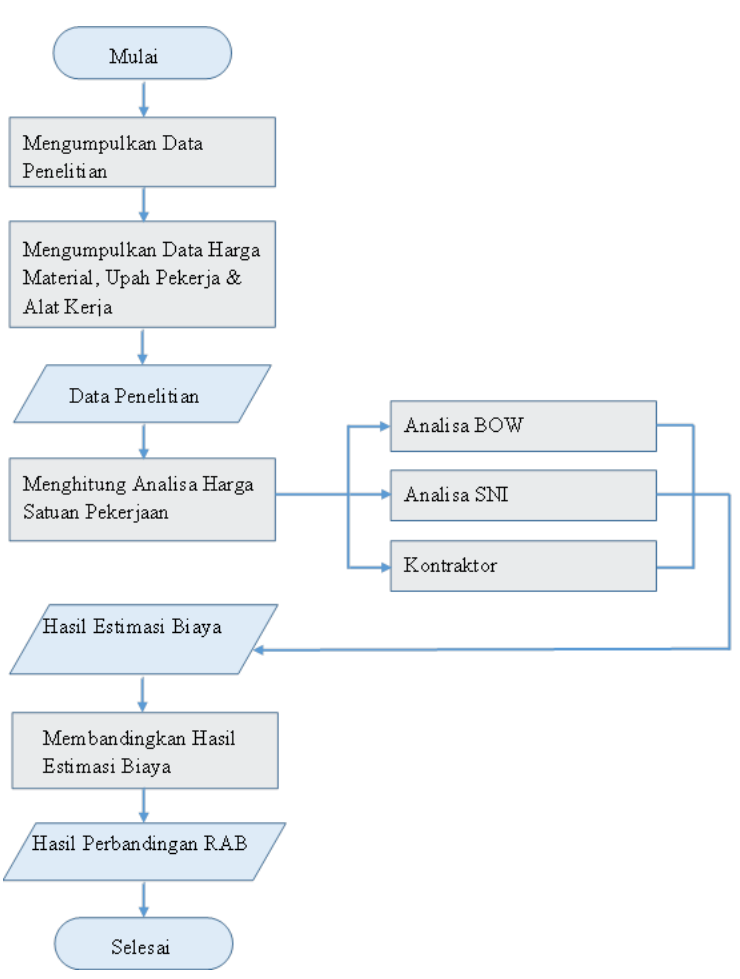

Gambar 3. Diagram Alir Penelitian

HASIL DAN PEMBAHASAN

HASIL

PT. Solusi Bangun Indonesia Tbk. (PT. SBI) bermaksud untuk memasang fasilitas jalur pengeluaran baru untuk semen, khusus dari semen silo 4 dan 5 ke mesin pengepakan yang baru (Ex-Batam Plant) dengan kapasitas 2400 bph, kemudian memasang transport equipment untuk semen bag dari mesin pengepakan baru tersebut ke alat palet baru dengan kapasitas 2400 bph. Fasilitas yang dibangun termasuk bangunan untuk packer, gallery conveyor dan bangunan untuk gudang semen bag dan pallet. Jenis Pekerjaan meliputi pekerjaan sipil dan mekanikal. Lokasi proyek di area pabrik PT. Solusi Bangun Indonesia Kecamatan Tambakboyo Kabupaten Tuban, Jawa Timur.

\section{Jenis Pekerjaan Obyek Penelitian}

Jenis pekerjaan yang dijadikan obyek penelitian adalah pekerjaan struktur beton yang meliputi :

1. Bangunan Palletizer
a. Foundation $\mathrm{F} 1$
b. Foundation F2
c. Foundation $\mathrm{F} 3$
d. Concrete Beam CB1

e. Pedestal HC3

f. Pedestal C6

g. Pedestal C7

h. Pedestal C8

i. Concrete Floor

2. Bangunan Packer

a. Foundation $\mathrm{F} 1$

b. Foundation $\mathrm{F} 2$

c. Foundation $\mathrm{F} 3$

d. Foundation F4

e. Foundation F5

f. Foundation F6

g. Concrete Beam CB1

h. Pedestal HC4

i. Pedestal HC5

j. Pedestal C7

k. Pedestal C8

I. Concrete Floor

m. Concrete Floor Elevasi +40.440

3. Gallery Conveyor
a. Foundation and Pedestal 1
b. Tie Beam 1
c. Foundation and Pedestal 2
d. Tie Beam 2

\section{Perhitungan Rencana Anggaran Biaya}

1. Perhitungan Analisa Biaya Konstruksi

Cara menghitung analisa biaya konstruksi atau harga satuan pekerjaan yaitu dengan cara mengalikan nilai koefisien analisa dengan harga satuan material dan upah pekerja. Harga material yang dipakai sebagai dasar perhitungan rencana anggaran biaya seperti pada tabel 1. Tabel 2 adalah daftar upah pekerja dan tabel 3 adalah daftar harga sewa alat kerja. 
Bambang Pilutomo $^{1 *}$, dan Hammam Rofiqi Agustapraja ${ }^{2}$

Tabel 1. Daftar Harga Material

\begin{tabular}{|c|c|c|c|}
\hline No & Nama Material & Satuan & Harga Satuan \\
\hline 1 & Kayu meranti campur & $\mathrm{m}^{3}$ & 4.250 .000 \\
\hline 2 & Kayu randu & $\mathrm{m}^{3}$ & 1.562 .500 \\
\hline 3 & Multiplek $4^{\prime} \times 8^{\prime} \mathrm{t}=12 \mathrm{~mm}$ & lembar & 215.000 \\
\hline 4 & Bambu 8m & btg & 53.333 \\
\hline 5 & Paku & $\mathrm{kg}$ & 21.500 \\
\hline 6 & Minyak bekisting & Itr & 22.500 \\
\hline 7 & Betonyser & $\mathrm{kg}$ & 9.400 \\
\hline 8 & Bendrat & $\mathrm{kg}$ & 19.200 \\
\hline 9 & Ready Mix K125 & $\mathrm{m}^{3}$ & 636.363 \\
\hline 10 & Ready Mix K250 & $\mathrm{m}^{3}$ & 792.454 \\
\hline 11 & Combextra Fosroc & sak & 155.000 \\
\hline 12 & Angkur M22 & bh & 86.500 \\
\hline 13 & Angkur M20 & bh & 80.500 \\
\hline 14 & Angkur M16 & bh & 76.500 \\
\hline 15 & Ready Mix K300 & $\mathrm{m}^{3}$ & 909.090 \\
\hline 16 & Wiremesh M8-150, 2,1m x 5,2m & lembar & 740.000 \\
\hline 17 & Plastik Cor LDPE, $1 \mathrm{~m} \times 50 \mathrm{~m} \mathrm{t}=0,15 \mathrm{~mm}$ & roll & 183.500 \\
\hline 18 & Steel Deck Zincalume $\mathrm{t}=0,7 \mathrm{~mm}$ & $\mathrm{~m}^{2}$ & 425.000 \\
\hline 19 & Semen Portland & $\mathrm{kg}$ & 1.325 \\
\hline 20 & Pasir Cor & $\mathrm{m}^{3}$ & 395.000 \\
\hline 21 & Koral & $\mathrm{m}^{3}$ & 470.000 \\
\hline 22 & Pasir Urug & $\mathrm{m}^{3}$ & 207.142 \\
\hline 23 & Air Kerja & Itr & 40 \\
\hline
\end{tabular}

Tabel 2. Daftar Upah Pekerja

\begin{tabular}{clcr}
\hline No & Spesifikasi Pekerja & Satuan & Harga Satuan \\
\hline 1 & Mandor & $\mathrm{O} / \mathrm{H}$ & 150.000 \\
2 & Kepala Tukang & $\mathrm{O} / \mathrm{H}$ & 135.000 \\
3 & Tukang batu & $\mathrm{O} / \mathrm{H}$ & 120.000 \\
4 & Tukang kayu & $\mathrm{O} / \mathrm{H}$ & 120.000 \\
5 & Tukang Besi & $\mathrm{O} / \mathrm{H}$ & 120.000 \\
6 & Pekerja & $\mathrm{O} / \mathrm{H}$ & 90.000 \\
\hline
\end{tabular}

Tabel 3. Daftar Sewa Alat Kerja

\begin{tabular}{cccr}
\hline No & Alat Kerja & Satuan & Harga Satuan \\
\hline 1 & Excavator PC200 & jam & 315.000 \\
2 & Dump Truck 10T & jam & 162.500 \\
\hline
\end{tabular}

Harga satuan pekerjaan $=$ koefisien $x$ harga satuan material dan upah.

Tabel 4 adalah contoh perhitungan analisa biaya konstruksi berdasarkan analisa BOW untuk pekerjaan galian tanah keras dengan kedalaman 1 meter. Dari tabel tersebut diketahui bahwa harga untuk pekerjaan $1 \mathrm{~m} 3$ galian tanah keras dengan kedalaman 1 meter adalah Rp. 94.950,-.

Cara perhitungannya sebagai berikut :

Diketahui :

Upah Pekerja $=$ Rp. 90.000,- orang per hari (lihat tabel 2)

Koefisien Pekerja $\quad=1,000$

Upah Mandor = Rp. 150.000,- orang per hari (lihat tabel 2)

Koefisien Mandor $\quad=0,033$

Harga Satuan Pekerjaan Galian Tanah

$=$ (koefisien Pekerja $\mathrm{x}$ Upah Pekerja $)+$ (Koefisien Mandor x Upah Mandor)

$=(1,000 \times$ Rp. 90.000,- $)+(0,033 \times$ Rp. $150.000,-)$

= Rp. 94.950,--

Jadi harga $1 \mathrm{~m} 3$ galian tanah keras kedalaman 1 meter adalah Rp. 94.950,-

Tabel 4. Contoh Perhitungan Analisa Biaya Konstruksi Berdasarkan Analisa BOW

\begin{tabular}{llrrrr}
\hline \multicolumn{6}{l}{$\mathrm{m}^{3}$ Galian Tanah Keras kedalaman $1 \mathrm{~m}$} \\
\hline No & \multicolumn{1}{c}{ Uraian } & Satuan & Koefisien & $\begin{array}{r}\text { Harga Satuan } \\
(\mathrm{Rp})\end{array}$ & $\begin{array}{r}\text { Jumlah Harga } \\
(\mathrm{Rp})\end{array}$ \\
\hline A & TENAGA & & & & \\
& Pekerja & OH & 1,000 & $90.000,00$ & $90.000,00$ \\
& Mandor & OH & 0,033 & $150.000,00$ & $4.950,00$ \\
& & & JUMLAH TENAGA KERJA & $94.950,00$ \\
B & BAHAN & & JUMLAH HARGA BAHAN & - \\
C & PERALATAN & & & \\
& & JUMLAH HARGA ALAT & - \\
D & Jumlah (A+B+C) & & & $94.950,00$ \\
\hline
\end{tabular}

Untuk menghitung analisa biaya konstruksi atau harga satuan pekerjaan berdasarkan analisa SNI dan perhitungan kontraktor dilakukan dengan cara yang sama.

Perhitungan analisa biaya konstruksi dilakukan dengan menggunakan bantuan program Microsoft excel versi 2010. Hasil perhitungan analisa biaya konstruksi dari ketiga analisa yang diteliti dan perbandinganya dapat dilihat pada tabel 5. Dari tabel 5 dapat diketahui bahwa analisa biaya konstruksi yang dihitung berdasarkan analisa BOW rata-rata lebih tinggi dibandingkan analisa biaya konstruksi yang dihitung berdasarkan analisa SNI. Analisa biaya konstruksi yang dihitung berdasarkan perhitungan kontraktor sebagian ada yang lebih rendah dan sebagian lainya lebih tinggi jika dibandingkan analisa biaya konstruksi metode BOW dan SNI. 
Tabel 5. Hasil Perhitungan dan Perbandingan Analisa Biaya Konstruksi

\begin{tabular}{|c|c|c|c|c|c|}
\hline \multirow{2}{*}{ No } & \multirow{2}{*}{ Jenis Pekerjaan } & \multirow{2}{*}{ Satuan } & \multicolumn{3}{|c|}{ Harga Satuan } \\
\hline & & & BOW & SNI & Kontraktor \\
\hline 1 & Galian Tanah Keras kedalaman $1 \mathrm{~m}$ & $1 \mathrm{~m}^{3}$ & $94.950,00$ & $65.550,00$ & $106.102,80$ \\
\hline 2 & Urugan Pasir & $1 \mathrm{~m}^{3}$ & $277.070,40$ & $277.070,40$ & $306.784,60$ \\
\hline 3 & $\begin{array}{l}\text { Beton Rabat } / \text { beton mutu fc } \pm=9,8 \\
\mathrm{MPa}(\mathrm{K} \mathrm{125}), \text { slump }(12 \pm 2) \mathrm{cm}, \mathrm{w} / \mathrm{c}= \\
0,78\end{array}$ & $1 \mathrm{~m}^{3}$ & $1.607 .995,00$ & $1.153 .975,00$ & $894.090,26$ \\
\hline 4 & $\begin{array}{l}\text { beton mutu } \mathrm{fc} \pm=21,7 \mathrm{MPa}(\mathrm{K} 250) \\
\text { slump }(12 \pm 2) \mathrm{cm}, \mathrm{w} / \mathrm{c}=0,56\end{array}$ & $1 \mathrm{~m}^{3}$ & $1.787 .275,00$ & $1.266 .505,00$ & $996.774,05$ \\
\hline 5 & $\begin{array}{l}\text { beton mutu } \mathrm{fc} \pm=26,4 \mathrm{MPa}(\mathrm{K} 300) \\
\text { slump }(12 \pm 2) \mathrm{cm}, \mathrm{w} / \mathrm{c}=0,52\end{array}$ & $1 \mathrm{~m}^{3}$ & $1.816 .035,00$ & $1.295 .265,00$ & $1.090 .907,75$ \\
\hline 6 & Grouting tidak campuran & $1 \mathrm{~m}^{3}$ & $11.486 .000,00$ & $11.486 .000,00$ & $12.416 .000,00$ \\
\hline 7 & Plastik Cor & $1 \mathrm{~m}^{2}$ & $4.979,40$ & $4.979,40$ & $4.687,00$ \\
\hline 8 & $\begin{array}{l}\text { Pembesian dengan besi polos atau } \\
\text { besi ulir }\end{array}$ & $1 \mathrm{~kg}$ & $28.386,50$ & $11.782,50$ & $12.243,00$ \\
\hline 9 & $\begin{array}{l}\text { Pasang Wiremesh M8x150 ( } 1 \text { lembar } \\
\text { ukuran } 2,1 \mathrm{~m} \times 5,2 \mathrm{~m} \text {, berat }=61,79 \mathrm{~kg} \text { ) }\end{array}$ & $1 \mathrm{~m}^{2}$ & $74.937,89$ & $74.937,89$ & $75.633,91$ \\
\hline 10 & $\begin{array}{l}\text { Pemasangan bekisting untuk pondasi } \\
2 X \text { kali pakai }\end{array}$ & $1 \mathrm{~m}^{2}$ & $127.225,00$ & $124.235,00$ & $98.825,00$ \\
\hline 11 & $\begin{array}{l}\text { Pemasangan bekisting untuk balok } 2 x \\
\text { pakai }\end{array}$ & $1 \mathrm{~m}^{2}$ & $253.046,67$ & $253.046,67$ & $204.641,67$ \\
\hline 12 & $\begin{array}{l}\text { Pemasangan bekisting untuk kolom } 2 x \\
\text { pakai }\end{array}$ & $1 \mathrm{~m}^{2}$ & $246.671,67$ & $246.671,67$ & $198.266,67$ \\
\hline 13 & Pengurugan kembali galian tanah & $1 \mathrm{~m}^{3}$ & $23.737,50$ & $20.130,00$ & $37.500,00$ \\
\hline 14 & Pasang Angkur M22 & $1 \mathrm{ttk}$ & $106.375,00$ & $106.375,00$ & $129.750,00$ \\
\hline 15 & Pasang Angkur M20 & $1 \mathrm{ttk}$ & $100.375,00$ & $100.375,00$ & $120.750,00$ \\
\hline 16 & Pasang Angkur M16 & $1 \mathrm{ttk}$ & $91.406,25$ & $91.406,25$ & $114.750,00$ \\
\hline 17 & $\begin{array}{l}\text { Construction Joint Detail } 1(1 \mathrm{~m}=1,77 \\
\mathrm{kg})\end{array}$ & $1 \mathrm{~m}^{1}$ & $50.244,11$ & $20.855,03$ & $21.670,11$ \\
\hline 18 & Bondex / Steel Deck Zincalume & $1 \mathrm{~m}^{2}$ & $546.155,00$ & $546.155,00$ & $490.250,00$ \\
\hline
\end{tabular}

Sumber : Hasil Penelitian

2. Perhitungan Rencana Anggaran Biaya

Di dalam penelitian ini, rencana anggaran biaya dihitung berdasarkan Bill of Quantity (BoQ) yang diterima oleh kontraktor pada saat rapat pemberian penjelasan (aanwijzing). BoQ tersebut sudah berisi rincian pekerjaan dan volumenya. Harga suatu pekerjaan diperoleh dari perkalian antara analisa biaya konstruksi atau harga satuan pekerjaan dengan volume pekerjaan yang ada di dalam BoQ.

Contoh cara perhitungan harga pekerjaan

Diketahui ;

Volume urugan pasir $\quad=3,872 \mathrm{~m} 3$

Analisa biaya konstruksi (ABK) untuk pekerjaan urug pasir per $\mathrm{m} 3$ menurut analisa BOW adalah Rp. 277.070,40.

Maka ;

Harga pekerjaan urug pasir = volume urug pasir $\mathrm{x}$ analisa biaya konstruksi
$=3,87 \mathrm{~m} 3$ x Rp. $277 \cdot 070,40$

$=$ Rp. 1.072.816,59

Untuk menghitung harga suatu pekerjaan berdasarkan analisa SNI dan perhitungan kontraktor dilakukan dengan cara yang sama.

Perhitungan RAB dilakukan menggunakan bantuan program Microsoft Excel versi 2010. Hasil perhitungan RAB berdasarkan ketiga metode dan perbandinganya seperti pada tabel 6 . Perbandingan hasil perhitungan rencana anggaran biaya bertujuan untuk mengetahui selisih harga dan persentase efisiensi harga antar ketiga metode yang diteliti. Selain itu juga untuk mengetahui metode mana yang paling kompetitif secara harga untuk dijadikan sebagai dasar penyusunan rencana anggaran biaya. 
Bambang Pilutomo $^{1 *}$, dan Hammam Rofiqi Agustapraja ${ }^{2}$

Tabel 6. Hasil Perhitungan dan Perbandingan RAB

\begin{tabular}{|c|c|c|c|c|}
\hline NO. & DESCRIPTION & $\begin{array}{c}\text { Harga BOW } \\
\text { (Rp) }\end{array}$ & $\begin{array}{l}\text { Harga SNI } \\
\text { (Rp) }\end{array}$ & $\begin{array}{c}\text { Harga } \\
\text { Perhitungan } \\
\text { Kontraktor } \\
\text { (Rp) }\end{array}$ \\
\hline & CIVIL WORKS & & & \\
\hline 3,1 & PALLETIZER BUILDING & & & \\
\hline 3.1 .1 & FOUNDATION F1 & 86.447 .576 & 52.887 .013 & 51.043 .479 \\
\hline 3.1 .2 & FOUNDATION F2 & 115.387 .059 & 71.644 .697 & 70.000 .309 \\
\hline 3.1 .3 & FOUNDATION F3 & 20.918 .169 & 12.663 .103 & 12.966 .399 \\
\hline 3.1 .4 & CONCRETE BEAM CB1 & 249.708 .228 & 167.273 .238 & 149.882 .862 \\
\hline 3.1 .5 & PEDESTAL HC3 & 46.709 .694 & 28.754 .825 & 28.184 .982 \\
\hline 3.1 .6 & PEDESTAL C6 & 6.346 .786 & 4.418 .575 & 4.347 .440 \\
\hline 3.1 .7 & PEDESTAL C7 & 51.888 .893 & 34.273 .571 & 33.653 .618 \\
\hline 3.1 .8 & PEDESTAL C8 & 9.830 .599 & 6.400 .948 & 6.378 .937 \\
\hline \multirow[t]{2}{*}{3.1 .9} & CONCRETE FLOOR & 1.444 .942 .784 & 1.138.978.907 & 1.020 .555 .021 \\
\hline & SUB TOTAL OF 3,1 PALLETIZER BUILDING & 2.032.179.789 & 1.517.294.877 & 1.377.013.046 \\
\hline 3,2 & PACKER BUILDING & & & \\
\hline 3.2 .1 & FOUNDATION F1 & 19.758 .241 & 11.347 .613 & 10.992 .170 \\
\hline 3.2 .2 & FOUNDATION F2 & 45.795 .172 & 26.547 .017 & 25.784 .941 \\
\hline 3.2 .2 & FOUNDATION F3 & 24.598 .660 & 14.024.892 & 13.823 .565 \\
\hline 3.2 .3 & FOUNDATION F4 & 22.989 .875 & 13.973.178 & 14.004 .226 \\
\hline 3.2 .4 & FOUNDATION F5 & 8.106 .500 & 4.941 .903 & 5.191 .260 \\
\hline 3.2 .5 & FOUNDATION F6 & 5.954 .164 & 3.587 .092 & 3.667 .983 \\
\hline 3.2 .6 & CONCRETE BEAM CB1 & 74.664 .510 & 50.005 .398 & 44.758 .443 \\
\hline 3.2 .7 & PEDESTAL HC4 & 23.929 .904 & 15.186 .639 & 14.670 .131 \\
\hline 3.2 .8 & PEDESTAL HC5 & 5.629 .175 & 3.836 .272 & 3.689 .256 \\
\hline 3.2 .9 & PEDESTAL C7 & 44.940 .224 & 31.793 .462 & 25.655 .611 \\
\hline 3.2 .10 & PEDESTAL C8 & 13.838 .292 & 9.639 .687 & 9.785 .819 \\
\hline 3.2.11 & CONCRETE FLOOR & 73.952 .617 & 57.468 .082 & 50.648 .107 \\
\hline \multirow[t]{2}{*}{ 3.2.12 } & CONCRETE ROOF EL. +40.440 (T.O.C) & 28.949 .354 & 26.605 .889 & 23.756 .950 \\
\hline & SUB TOTAL OF 3,2 PACKER BUILDING & 393.106 .688 & 268.957 .123 & 246.428 .462 \\
\hline 3,3 & GALLERY CONVEYOR & & & \\
\hline 3.3 .1 & FOUNDATION \& PEDESTAL 1 & 75.296 .163 & 45.957 .104 & 44.886 .275 \\
\hline 3.3 .2 & TIE BEAM 1 & 48.652 .569 & 37.054 .600 & 31.442 .874 \\
\hline 3.3 .3 & FOUNDATION \& PEDESTAL 2 & 90.355 .396 & 55.148 .524 & 53.863 .530 \\
\hline \multirow[t]{3}{*}{ 3.3.4 } & TIE BEAM 2 & 42.724 .407 & 33.590 .154 & 28.322.296 \\
\hline & SUB TOTAL OF 3,3 GALLERY CONVEYOR & 257.028 .536 & 171.750 .381 & 158.514 .976 \\
\hline & GRAND TOTAL & 2.682 .315 .013 & 1.958 .002 .381 & 1.781 .956 .484 \\
\hline
\end{tabular}

Sumber : Hasil Penelitian

Perbandingan harga RAB untuk Palletizer Building seperti grafik pada gambar 4. Pada grafik tersebut terlihat bahwa harga tertinggi dari estimasi anggaran biaya adalah yang dihitung berdasar analisa BOW, tertinggi kedua adalah SNI dan yang paling rendah adalah perhitungan kontraktor.

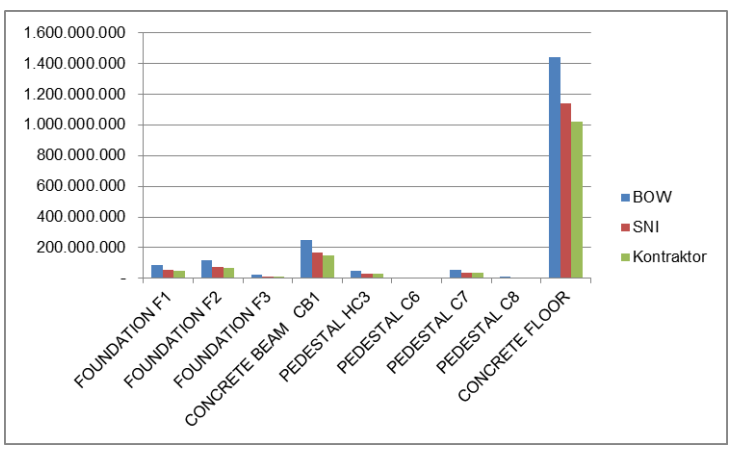

Gambar 4. Grafik Perbandingan Harga Palletizer Building 
Perbandingan harga RAB untuk Packer Building seperti grafik pada gambar 5. Pada grafik tersebut terlihat bahwa harga tertinggi dari estimasi anggaran biaya adalah yang dihitung berdasar analisa BOW, tertinggi kedua adalah $\mathrm{SNI}$ dan yang paling rendah adalah perhitungan kontraktor.

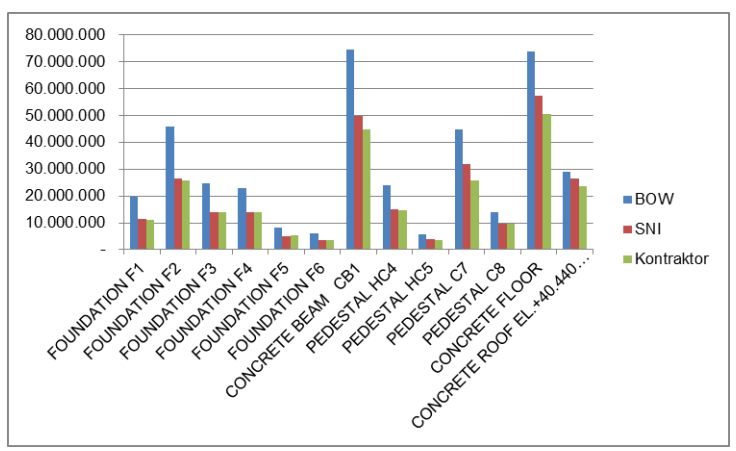

Gambar 5. Grafik Perbandingan Harga Packer Building

Perbandingan harga RAB untuk Gallery Conveyor seperti grafik pada gambar 6 . Pada grafik tersebut terlihat bahwa harga tertinggi dari estimasi anggaran biaya adalah yang dihitung berdasar analisa BOW, tertinggi kedua adalah $\mathrm{SNI}$ dan yang paling rendah adalah perhitungan kontraktor.

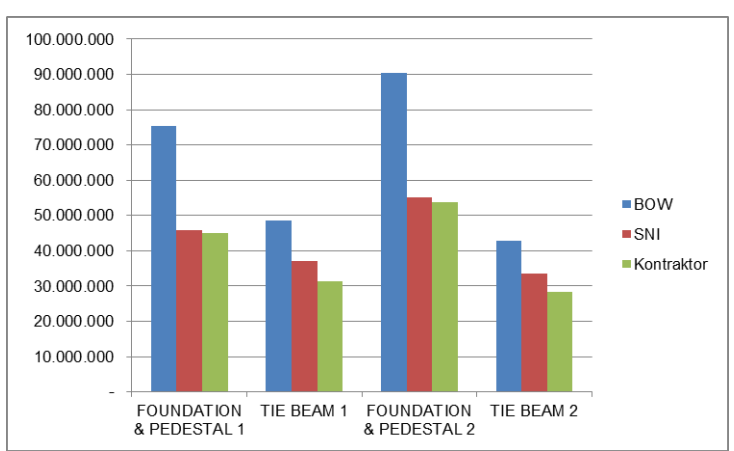

Gambar 6. Grafik Perbandingan Harga Gallery Conveyor

\section{PEMBAHASAN}

Dari hasil penelitian diketahui bahwa harga yang paling ekonomis adalah harga yang dihitung berdasarkan analisa perhitungan kontraktor yaitu sebesar Rp. 1.781.956.483,-. Harga tersebut efisien 8,99\% dari harga yang dihitung berdasarkan analisa SNI dan efisien $33,57 \%$ dari harga yang dihitung berdasarkan analisa BOW. Harga yang dihitung berdasarkan analisa $\mathrm{SNI}$ berada di urutan kedua sebesar Rp. 1.958.002.381,-, efisien $27,00 \%$ dari harga yang dihitung berdasarkan analisa BOW. Sedangkan harga yang dihitung berdasarkan analisa BOW adalah harga yang paling mahal sebesar Rp. 2.682.315.013,-. Rincian dan perbandingan hasil perhitungan rencana anggaran biaya dari ketiga metode dan selisih harganya dapat dilihat pada tabel 7. Persentase selisih harga antar ketiga metode dapat dilihat di tabel 8.

Tabel 8. Persentase Selisih Harga RAB

\begin{tabular}{ccc}
\hline \multicolumn{3}{c}{ Persentase Selisih Harga (\%) } \\
\hline BOW vs SNI & $\begin{array}{c}\text { BOW vs } \\
\text { Kontraktor }\end{array}$ & $\begin{array}{c}\text { SNI vs } \\
\text { Kontraktor }\end{array}$ \\
\hline $27,00 \%$ & $33,57 \%$ & $8,99 \%$ \\
\hline
\end{tabular}

Perbedaan harga disebabkan adanya perbedaan koefisien di masing-masing analisa yang diteliti. Koefisian analisa BOW lebih tinggi dibanding dengan koefisien analisa SNI. Koefisien perhitungan kontraktor sebagian ada yang lebih tinggi dan sebagian lainya lebih rendah dibanding koefisien analisa BOW dan SNI. Perbedaan yang signifikan adalah pada koefisien di tenaga kerja. Koefisian di analisa kebutuhan material dari ketiga analisa hampir sama.

Dari penelitian ini diketahui bahwa selisih harga terbesar adalah selisih harga antara harga perhitungan kontraktor dengan harga BOW yaitu sebesar Rp. 900.358.529,-. Selisih harga BOW dengan harga SNI sebesar Rp. 724.312.631,--. Selisih harga perhitungan kontraktor dengan harga SNI sebesar Rp. 176.045.897,--.

Penelitian ini dilakukan tanpa memperhitungkan keuntungan, biaya-biaya

Tabel 7. Hasil Perhitungan dan Selisih Harga RAB

\begin{tabular}{|c|c|c|c|c|c|}
\hline \multicolumn{3}{|c|}{ Nilai Rencana Anggaran Biaya (Rp.) } & \multicolumn{3}{|c|}{ Selisih Harga (Rp.) } \\
\hline BOW & SNI & Kontraktor & $\mathrm{BOW}$ vs SNI & $\begin{array}{l}\text { BOW vs } \\
\text { Kontraktor }\end{array}$ & $\begin{array}{c}\text { SNI vs } \\
\text { Kontraktor }\end{array}$ \\
\hline
\end{tabular}

$\begin{array}{lllllll}2.682 .315 .013,21 & 1.958 .002 .381,35 & 1.781 .956 .483,87 & 724.312 .631,86 & 900.358 .529,34 & 176.045 .897,48\end{array}$ 
Bambang Pilutomo ${ }^{1 *}$, dan Hammam Rofiqi Agustapraja²

tidak langsung dan biaya keselamatan dan kesehatan kerja (K3). Selain itu, penelitian ini juga dibatasi dilakukan terhadap pekerjaan konstruksi beton saja. Dengan memasukkan keuntungan, biaya-biaya tidak langsung dan biaya K3, mungkin akan diperoleh hasil yang berbeda. Namun, penelitian ini telah bisa memberikan jawaban bahwa harga perhitungan kontraktor adalah harga yang paling efisien, disusul oleh harga SNI dan yang paling tidak efisien adalah analisa BOW.

\section{Kesimpulan}

\section{PENUTUP}

Dari hasil penelitian di atas terkait perbandingan estimasi anggaran biaya antara metode SNI, BOW dan perhitungan kontraktor pada tender Shipout Cement Debottlenecking Project dapat diambil kesimpulan sebagai berikut :

1. Metode pembuatan perhitungan anggaran biaya menggunakan analisa BOW, analisa SNI dan perhitungan Kontraktor dihitung berdasarkan pada analisa biaya konstruksi mengacu kepada nilai koefisien dari ketiga metode tersebut. Adanya perbedaan harga disebabkan karena adanya perbedaan nilai koefisien, dimana nilai koefisien tersebut dipengaruhi oleh pemilihan metode pelaksanaan pekerjaan yang dipakai, efektifitas pekerja dan efisiensi penggunaan material.

2. Dari perhitungan $R A B$, harga berdasarkan analisa BOW sebesar Rp. 2.682.315.013,21, harga berdasarkan analisa SNI sebesar Rp. 1.958.002.381,35 dan harga berdasarkan perhitungan kontraktor sebesar Rp. 1.781.956.483,87. Selisih harga antara harga perhitungan kontraktor dengan harga BOW yaitu sebesar Rp. 900.358.529,-. Selisih harga antara harga SNI dengan harga BOW sebesar Rp. 724.312.632,-. Selisih harga perhitungan kontraktor dengan harga SNI sebesar Rp. 176.045.897,-. Harga perhitungan kontraktor $8,99 \%$ lebih efisien dari harga SNI dan 33,57\% lebih efisien dari harga BOW. Harga SNI 27,00 \% lebih efisien dari harga BOW.

3. Rencana Anggaran Biaya yang paling kompetitif secara harga adalah yang dihitung berdasarkan perhitungan kontraktor.

\section{Saran}

1. Di dalam menghitung harga satuan pekerjaan sebaiknya dilakukan perhitungan dengan lebih teliti, khususnya pemilihan metode perhitungan yang tepat sehingga didapatkan anggaran biaya yang ekonomis serta dapat dipertanggung jawabkan.

2. Metode BOW sebaiknya tidak dipakai lagi di dalam menentukan anggaran biaya proyek karena sudah tidak relevan lagi untuk saat ini. Kontraktor, terutama yang mengikuti tender di perusahaan swasta, diharapkan memiliki analisa perhitungan sendiri berdasarkan pengalaman kerja di lapangan. Perhitungan kontraktor bisa mengacu pada analisa SNI yang disesuaikan koefisien analisanya.

3. Untuk penelitian berikutnya agar membuat perbandingan estimasi anggaran biaya pada pekerjaan di lingkungan industri yang menerapkan peraturan safety secara ketat dan memperhitungkan biaya keselamatan dan kesehatan kerja (K3).

\section{DAFTAR PUSTAKA}
Anonim. (1984). Analisa (Cara Modern) Anggaran Biaya Pelaksanaan, Bandung: Nova.

Anonim. (1984). Analisa (Cara Modern) Anggaran Biaya Pelaksanaan Lanjutan, Bandung: Nova.Badan Standarisasi Nasional (BSN) (2018). Kumpulan Analisa Biaya Konstruksi Bangunan Gedung dan Perumahan.

Heryanto, I. \& Triwibowo, T. (2009). Manajemen Proyek Berbasis Teknologi Informasi. Cetakan Pertama. Bandung: Informatika Bandung.

Project Management Institute (2013). Project Management Body of Knowledge (PMBOK Guide): 5.

Redaksi Bumi Aksara (1993). Analisa Upah dan Bahan (Analisis BOW, Jakarta: Bumi Aksara.

Santosa, B. (2009). Manajemen Proyek, Konsep \& Implementasi. Cetakan Pertama. Yogyakarta: Graha IImu. 
Susanta, G. (2009). Cara Cepat Menghitung Biaya Membangun Rumah. Cetakan Pertama. Depok: Penebar Swadaya.

Widiasanti, I \& Lenggogeni (2013). Manajemen Konstruksi. Cetakan Pertama. Bandung: PT. Remaja Rosdakarya.

Agustapraja, H. R., \& Affandy, N. A. (2017). PERBANDINGAN ESTIMASI ANGGARAN BIAYA DENGAN METODE SNI DAN BOW PADA PROYEK PEMBANGUNAN GEDUNG D FAKULTAS AGAMA ISLAM UNIVERSITAS ISLAM LAMONGAN. UKaRsT, 1(2), 1-9.

Budi, M. R. S. (2018). Perbandingan Estimasi Anggaran Biaya dan Schedule Proyek Pembangunan Rumah Sakit Al Huda Banyuwangi Menggunakan Metode SNI Dan Metode Bow (Doctoral dissertation, UNIVERSITAS MUHAMMADIYAH JEMBER).

Kusuma, M. S. T. S. (2018). ANALISIS PERBANDINGAN ESTIMASI ANGGARAN BIAYA PADA PEKERJAAN STRUKTUR ATAS ANTARA METODE BOW, SNI DAN KONTRAKTOR Studi Kasus: Proyek Hotel Cordela Yogyakarta (Doctoral dissertation, University of Technology Yogyakarta).

MH, A. A. P. (2011). Perbandingan Estimasi Anggaran Biaya Antara Metode Bow, SNI, dan Kontraktor. Proceeding PESAT (Psikologi, Ekonomi, Sastra, Arsitektur \&Sipil), 4.

Mufaris, A., Prihesnanto, F., \& Darma, E. (2016). Perbandingan Estimasi Anggaran Biaya antara Bow, Sni dan Metode Perhitungan Kontraktor pada Proyek Rumah Susun (Rusun) Pulogebang Jakarta Timur. Bentang, 4(1).

Putra, M. R., \& Affandy, N. A. (2017). PERBANDINGAN ESTIMASI ANGGARAN BIAYA DENGAN METODE SNI DAN BOW. Jurnal CIVILA, 2(1).

RAHMAN, A. (2015). PERBANDINGAN ESTIMASI ANGGARAN BIAYA ANTARA METODE SNI DAN BOW PADA PROYEK PEMBANGUNAN GEDUNG JOANG/LEGIUN VETERAN
REPUBLIK

INDONESIA

SAMARINDA. KURVA S JURNAL

MAHASISWA, 4(1), 620-639.

Rahman, I. A., Warman, H., \& Taufik, T. (2018). PERBANDINGAN ESTIMASI ANGGARAN BIAYA DENGAN MEMAKAI ANALISA SNI DAN ANALISA BOW (STUDI KASUS: PROYEK PEMBANGUNAN GEDUNG FAKULTAS EKONOMI DAN BISNIS ISLAM IAIN

BATUSANGKAR). Abstract of Undergraduate Research, Faculty of Civil and Planning Engineering, Bung Hatta University, 2(2).

RAHMAN, R. N. (2018). PERBANDINGAN RENCANA ANGGARAN BIAYA ANTARA METODE BOW DAN SNI PADA PEKERJAAN PERLUASAN GEDUNG LABORATORIUM BBPOM SAMARINDA. KURVA S JURNAL MAHASISWA, 4(2), 1661-1666. 